\title{
Prolonged prone position ventilation for SARS-CoV-2 patients is feasible and effective
}

\author{
Andrea Carsetti ${ }^{1,2}$, Agnese Damia Paciarini ${ }^{1,2}$, Benedetto Marini ${ }^{2}$, Simona Pantanetti ${ }^{2}$, Erica Adrario ${ }^{1,2}$ and \\ Abele Donati ${ }^{1,2^{*}}$ (D)
}

Keywords: SARS-CoV-2, Prone position ventilation

Recently, novel coronavirus 2019 (nCOV-19) is spreading all around the world causing severe acute respiratory syndrome (SARS-CoV-2) requiring mechanical ventilation in about $5 \%$ of infected people $[1,2]$. Prone position ventilation is an established method to improve oxygenation in severe acute respiratory distress syndrome (ARDS), and its application was able to reduce mortality rate [3]. Although the severity of critically ill patients with SARS-CoV-2 may require pronation [4], the huge number of patients requiring intensive care unit (ICU) admission may create management problems due to the limited number of healthcare workers compared to the number of patients. Often, sustained oxygenation improvement can only be achieved after several cycles of pronation, with a work overload for healthcare staff. To face these problems, we implemented a pronation protocol that allows to extend the time for the prone position beyond $16 \mathrm{~h}$, aiming to reduce the number of pronation cycles per patient. Thus, the aim of this report was to assess the feasibility and efficacy of prone position ventilation beyond the usual $16 \mathrm{~h}$.

We retrospectively collected data from 10 critically ill patients intubated and mechanically ventilated for SARS-CoV-2. Six patients underwent both standard and prolonged pronation, the latter after one standard cycle

\footnotetext{
* Correspondence: a.donati@univpm.it

${ }^{1}$ Department of Biomedical Sciences and Public Health, Università Politecnica delle Marche, Ancona, Italy

${ }^{2}$ Anesthesia and Intensive Care Unit, Azienda Ospedaliero Universitaria

Ospedali Riuniti, Ancona, Italy
}

failure; 3 patients underwent prolonged pronation only and 1 patient just to the standard one. We recorded $\mathrm{PaO}_{2} / \mathrm{FiO}_{2}$ values before pronation (T0), during pronation (T1), and in the supine position after the pronation cycle (T2). Friedman's test has been used for comparisons, considering a $p$ value $<0.05$ as significant.

All patients were male, with a median age of 58 years (IQR 50; 64). Six patients (54.4\%) were obese. All standard pronation cycles lasted for $16 \mathrm{~h}$ whereas the median duration of prolonged pronation cycles was $36 \mathrm{~h}$ (IQR 33.539). Ventilatory parameters before the first pronation trial are listed in Table 1. Oxygenation significantly improved during ventilation in prone position (Fig. 1). Interestingly, $\mathrm{PaO}_{2} / \mathrm{FiO}_{2}$ recorded in the supine position after a prolonged pronation trial was significantly higher than $\mathrm{PaO}_{2} /$ $\mathrm{FiO}_{2}$ measured before pronation $(p=0.034)$. On the other hand, the gain in oxygenation was not maintained after the standard pronation cycle $(p=0.423)$. Static compliance of the respiratory system did not change significantly following prone position ventilation $(p>0.05)$. Application of prolonged prone position did not expose patients to an increased incidence of skin pression lesions, and other complications were not reported.

Our report showed that prone position beyond $16 \mathrm{~h}$ may probably be safely performed in patients with SARS-CoV-2 and severe hypoxemia not responsive to conventional mechanical ventilation. This approach might have several potential advantages. First, oxygenation improvement might be higher during prolonged pronation than during standard pronation, and the gain 
Table 1 Patients' baseline characteristics

\begin{tabular}{ll}
\hline $\mathrm{FiO}_{2}$ & $0.7(0.18)$ \\
PEEP $\left(\mathrm{cmH}_{2} \mathrm{O}\right)$ & $14(1.49)$ \\
Pplat $\left(\mathrm{cmH}_{2} \mathrm{O}\right)$ & $24(1.94)$ \\
$\triangle P\left(\mathrm{cmH}_{2} \mathrm{O}\right)$ & $9.5(2.87)$ \\
$\mathrm{Cstat}\left(\mathrm{ml} / \mathrm{cmH} \mathrm{C}_{2} \mathrm{O}\right)$ & $49(9.24)$ \\
$\mathrm{PaO}_{2} / \mathrm{FiO}_{2}(\mathrm{mmHg})$ & $119(33.65)$
\end{tabular}

Data reported as mean (standard deviation)

Cstat static compliance of the respiratory system, $\triangle P$ driving pressure, $\mathrm{FiO}_{2}$ fraction of inspired oxygen, $\mathrm{PaO}_{2}$ arterial partial pressure of oxygen, $P E E P$ positive end-expiratory pressure, Pplat plateau pressure

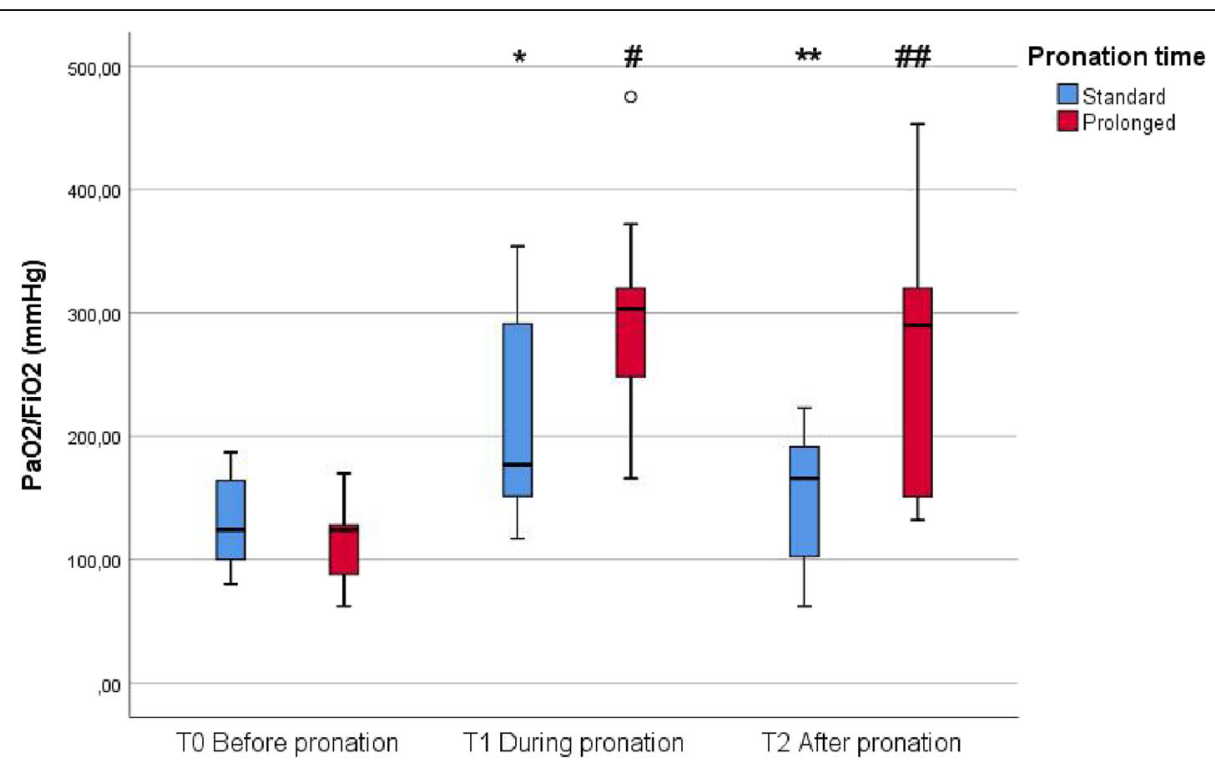

Fig. $1 \mathrm{PaO}_{2} / \mathrm{FiO}_{2}$ comparison between standard and prolonged prone position ventilation. *Standard pronation: T1 vs. T0, $p=0.01$; **standard pronation: T2 vs. T1, $p=0.016$; " prolonged pronation: T1 vs. T0, $p<0.001$; \#\# prolonged pronation: T2 vs. T0, $p=0.034$ 
might be more sustained over time. Second, in the condition of work overload for healthcare assistants, this strategy might reduce the number of pronation cycles needed for a single patient. Finally, no adverse events have been observed following this approach. However, a well-trained healthcare team is mandatory to perform the procedure, to rapidly face potential complications, and to guarantee appropriate patient preparation to reduce the risk of bedsore lesions. The team experience may be a potential problem during the pandemic because the recruitment of staff without a critical care background may be needed in ICUs to cope with personnel shortage. Obviously, these data must be interpreted with caution and need to be confirmed because of the small number of patients considered and the retrospective design of the study.

In conclusion, we showed that prolonged prone position up to $36 \mathrm{~h}$ is feasible, safe, and may offer potential clinical and organizational advantages.

\section{Abbreviations}

$\triangle P$ : Driving pressure; ARDS: Acute respiratory distress syndrome; Cstat: Static compliance of the respiratory system; $\mathrm{FiO}_{2}$ : Fraction of inspired oxygen; ICU: Intensive care unit; IQR: Interquartile range; nCOV-19: Novel coronavirus 2019; $\mathrm{PaO}_{2}$ : Arterial partial pressure of oxygen; PEEP: Positive end-expiratory pressure; Pplat: Plateau pressure; SARS-CoV-2: Severe acute respiratory syndrome

\section{Acknowledgements}

Not applicable

\section{Authors' contributions}

AC performed the statistical analysis, interpreted the results, and drafted the manuscript. ADP collected the data and interpreted the study results. BM, SP, and EA interpreted the study result and substantially revised the manuscript. AD designed the study and substantially revised the manuscript. All authors read and approved the final manuscript.

\section{Funding}

None.

\section{Availability of data and materials}

The datasets used and/or analyzed during the current study are available from the corresponding author on reasonable request.

\section{Ethics approval and consent to participate}

As a retrospective study design, the study protocol has been submitted to the Ethics Committee "Comitato Etico Regione Marche" for

acknowledgment.

\section{Consent for publication}

Not applicable.

\section{Competing interests}

The authors declare that they have no competing interests.

Received: 10 April 2020 Accepted: 7 May 2020

Published online: 15 May 2020

\section{References}

1. Yang X, Yu Y, Xu J, Shu H, Xia J, Liu H, et al. Clinical course and outcomes of critically ill patients with SARS-CoV-2 pneumonia in Wuhan, China: a singlecentered, retrospective, observational study. Lancet Respir. Med. 2020; [Epub ahead of print].
2. Guan W-J, Ni Z-Y, Hu Y, Liang W-H, Ou C-Q, He J-X, et al. Clinical characteristics of coronavirus disease 2019 in China. N. Engl. J. Med. 2020; [Epub ahead of print].

3. Guérin C, Reignier J, Richard JC, Beuret P, Gacouin A, Boulain T, et al. Prone positioning in severe acute respiratory distress syndrome. N Engl J Med. 2013:368:2159-68

4. World Health Organization. Clinical management of severe acute respiratory infection (SARI) when COVID-19 disease is suspected: interim guidance; 2020. p. 1-19.

\section{Publisher's Note}

Springer Nature remains neutral with regard to jurisdictional claims in published maps and institutional affiliations.
Ready to submit your research? Choose BMC and benefit from:

- fast, convenient online submission

- thorough peer review by experienced researchers in your field

- rapid publication on acceptance

- support for research data, including large and complex data types

- gold Open Access which fosters wider collaboration and increased citations

- maximum visibility for your research: over $100 \mathrm{M}$ website views per year

At BMC, research is always in progress.

Learn more biomedcentral.com/submissions 